\title{
Mutational analysis of selected high-grade malignancies in a premenopausal gynecologic cancer population: a potential for targeted therapies?
}

Lauren Pinckney ${ }^{1}$, Justin Collins ${ }^{2}$, Christine M. G. Schammel ${ }^{3}$, Matt Gevaert ${ }^{4}$, David P. Schammel ${ }^{3}$, W. Jeffrey Edenfield ${ }^{2}$, Jeffrey Elder ${ }^{5}$ and Larry E. Puls ${ }^{5^{*}}$

\begin{abstract}
Background: In 2017, there will be 107,000 cases of gynecologic cancer diagnosed in the US with an overall survival of around $70 \%$-most occurring in post-menopausal individuals. In this study, we have examined a younger ( $\leq 40$ years of age) subpopulation of these women with high grade/ high stage gynecologic malignancies, attempting to identify unique genetic abnormalities or combinations thereof through tissue block specimens. This information was then analyzed in light of known target therapies to see if genetic analysis in this setting would yield significant therapeutic advantage.

Methods: We retrospectively evaluated patients with high grade/high stage gynecologic cancers ( $\leq 40$ years of age), examined the presence and status of 400 oncogenes and tumors suppressor genes from Formalin-fixed, Paraffin-embedded (FFPE) tissue and functionally classified mutations by SIFT and Polyphen.

Results: Twenty women were identified and stratified into positive and negative outcomes. No demographic, clinicopathologic or treatment factors were significant between these groups. Of the 400 genes evaluated, twelve mutations were significant between the groups, six with targeted therapies. Mutations associated with negative outcomes within histologies/locations were evaluated: ERBB3 in epithelial (ovarian), ALK/GPR124/KMT2D in neuroendocrine (ovarian/endometrial), ROS1/EGFR, ROS1/ERBB3/KMT2D/NIRK1 and GPR124 in sarcoma. All negative outcomes were void of mutations in APC/ABL2. A predictive model for negative outcomes in our cohort was developed from these data: AKAP9-/MBD1-/APC-/ABL2- with a mutation load of > 20.5.
\end{abstract}

Conclusions: Unique multi-gene and mutational outcome correlations were identified in our cohort. Resulting complex mutational profiles in distinctly aggressive gynecologic cancers suggested potential for novel therapeutic treatment. Future larger scale studies will be needed to correlate the genotypic and phenotypic features identified here.

Keywords: Rare gynecologic cancers, Young women, Molecular profile, Predictive modeling

\footnotetext{
* Correspondence: Ipuls@ghs.org

${ }^{5}$ Greenville Health System Cancer Institute, Greenville Health System, 900 W

Faris Rd, Greenville, SC 29605, USA

Full list of author information is available at the end of the article
}

(c) The Author(s). 2018 Open Access This article is distributed under the terms of the Creative Commons Attribution 4.0 International License (http://creativecommons.org/licenses/by/4.0/), which permits unrestricted use, distribution, and reproduction in any medium, provided you give appropriate credit to the original author(s) and the source, provide a link to the Creative Commons license, and indicate if changes were made. The Creative Commons Public Domain Dedication waiver (http://creativecommons.org/publicdomain/zero/1.0/) applies to the data made available in this article, unless otherwise stated. 


\section{Introduction}

In 2017, approximately 107,000 new gynecologic cancers will occur in the United States [1]. Within this patient population, 61,000 individuals will be diagnosed with a malignancy of the uterine corpus, 22,000 of the ovary, and 13,000 of the cervix. The overall survival for this cohort is just under $70 \%$. In examining the demographics of this population, most affected individuals are post-menopausal with $12 \%$ of the ovarian cancer patients $<45$ years of age accounting for $3.1 \%$ of all ovarian cancer deaths. Similarly, 2.3 and $18.7 \%$ of endometrial and cervical cancer deaths, respectively, occur in patients $<45$ years [2].

There is growing evidence that certain identifiable mutational aberrations may be therapeutically targetable by novel treatment approaches $[3,4]$. As such, personalized medicine is gaining traction leading practitioners to expedite genetic testing, revealing information that identifies unique approaches to cancer treatment $[5,6]$. Increasingly, next generation sequencing methods have allowed clinicians to ascertain the presence of driver mutations, which can be precisely targeted with novel therapeutics. Patients with uncommon malignancies, advanced stage cancers, and those referred for Phase I trials, have been shown to derive therapeutic insight from genomic analysis [7].

This study was designed to evaluate a select group of patients ( $\leq 40$ years of age) with high-grade and/or advanced-staged gynecologic cancers treated in a single institution. Unique genetic abnormalities were analyzed from formalin-fixed paraffin embedded (FFPE) tissue, outcomes were correlated to mutational combinations and pooled genetic information was assessed for applicable novel treatment options.

\section{Patients and methods}

A series of gynecologic cancers diagnosed between (1/1/ 2010 and 12/31/2013) were retrospectively analyzed following IRB approval. Inclusion criteria were high grade and/or high stage cancers, $\leq 40$ years of age at diagnosis and treatment at a single regional cancer institute. Standard demographic and clinicopathologic data were collected. Each case had a probable site of origin in the ovary, uterus, or cervix and all cancers were considered primary tumors. Clinical and FIGO staging was completed by a gynecologic oncologist. One critical exclusion criterion was less than adequate tumor volume from FFPE for molecular analyses.

A gynecologic pathologist verified the status, location, stage (TNM), histologic subtype and cell type of the tumors for each patient included in the study. After verification of suitability for molecular analysis, micron sections of FFPE tumor tissue were cut and prepared for molecular analysis. Ion AmpliSeq ${ }^{\mathrm{Tm}}$ Comprehensive Cancer
Panel (ThermoFisher Scientific, Waltham, MA; Additional file 1: Table S1), was completed for each primary tumor (Selah Technologies, Greenville, SC). Mutations were evaluated by functional predictive algorithms to predict involvement in carcinogenesis [8-10]. Mutations identified as functionally relevant were evaluated for targeted therapies [11].

For analyses, our small number of patients was grouped into two cohorts as defined by outcome. Days of survival were calculated from diagnosis to either death or the end of the study. Positive outcomes were defined as survival greater than the median of the entire cohort and/or patients alive and disease free at the end of the study; positive outcomes were assigned to patients enrolled later the in the study period that also met these metrics despite days of survival less than the median. Negative outcomes were defined as survival less than the median of the entire cohort. The two groups were compared using 1- and 2-tailed t-tests, as well as ANOVA analysis for continuous variables (alpha $=0.05$ ). Classification and Regression Tree (CART) analysis was used to develop a model predictive of outcome [12] from the genetic profiles (Salford Systems' SPM7 software; http:// www.salford-systems.com; San Diego, CA) for classifying patients as either high or low risk. All data was analyzed with the understanding that with smaller cohorts, analysis is biased toward type-II errors (false negatives) and that the likelihood of Type-I errors (false positives) is contingent upon the alpha level, not the cohort size. Additionally, since the power of small cohorts is lower, a larger deviation from the null hypothesis (a larger effect) or an alternative hypothesis strongly supported by the data was to be observed if the null hypothesis was to be rejected without changing the alpha level.

\section{Results}

Twenty women were included in the study with a mean of survival of 563 days (range 15-2333; median 469; Additional file 2: Table S2) resulting in the classification of 14 patients with 'positive' outcomes and 6 patients with 'negative outcomes'. No significant differences were found in demographic factors (age, race, BMI, tobacco use and diagnosis of a previous cancer; Additional file 2: Table S2) between the cohorts. ECOG scores between the cohorts were insignificant with nineteen patients having scores of 0 , and one patient having a score of 2 (Additional file 2: Table S2). All lesions within each subtype were considered high-grade (Additional file 3: Table S3).

Ovarian cancer was the most frequent malignancy in the study population (60\%) with the epithelial histologic subtype accounting for $50 \%$ of the cancers followed by neuroendocrine and sarcoma (20 and 15\%, respectively). Histologic grading of the tumors revealed $85 \%$ grade III (correlating to $30 \%$ FIGO stage I, 45\% FIGO stage III; all 
patients had high grade histology and/or high stage disease); however, none of these factors were significantly associated with outcome (Additional file 2: Table S2).

All patients underwent surgical intervention (data not shown) and the majority received chemotherapy per standard of care $(n=17 ; 85 \%)$. Five patients received radiation therapy (25\%). All-together, none of these factors were significantly associated with outcome (Additional file 2: Table S2).

Molecular analysis revealed that of the 400 genes examined for mutations (Additional file 1: Table S1), 230 had mutations predicted to code for dysfunctional proteins (data not shown). Of these, 218 were not significantly associated with outcomes. T-tests (1- and 2-tailed) revealed 12 gene mutations significantly different between the outcome groups (Table 1). Mutational targeted therapy was identified for six (50\%) of these genetic abnormalities; none are approved for use in gynecologic cancers. One mutation (8\%), ERBB3, has targeted therapy in clinical trials for use in Non-Small Cell Lung Cancer (NSCLC) and breast cancer, while five did not have discrete targeted therapies. However, three of these $(60 \%)$ are associated with cellular pathways involved in drug metabolism (GPR124, CMPK1, MBD1) and two (40\%) of the mutations (KMT2D and AKAP9) are associated with carcinogenesis and thus being examined as possible candidates for targeted therapy (Table 1).

An evaluation of the three main histologic profiles and the genes associated with each phenotype per the literature is outlined in Tables 2, 3 and 4. The epithelial profile $(n=11)$, the largest group, including serous, clear cell, mucinous and endometrioid carcinomas (data not shown), had demographics mirroring the entire cohort (Table 2). Of the genes associated with this phenotype, none were significantly associated with the phenotype in our cohort. Within this profile, primary tumors were identified in the ovary (64\%), cervix (18\%) and endometrium (18\%). Carboplatin/Taxol was given as the chemotherapy regimen to $91 \%$ of the patients, with one patient receiving Platinum/Etoposide (cervix; Table 2). Three of the patients (cervix/endometrial) received radiation therapy; none of the patients with ovarian malignancies received radiation therapy. For novel targets identified by molecular typing, the greatest number of potential targets was found in ovarian tumors (six; AKAP9, CMPK, MBD1, ASXL1, ERBB3, KMT2D), while four were identified in the endometrial group (CMPK, MBD1, ROS1, GPR124). No significant targetable gene mutations were identified in the cervix group. In correlating outcomes with gene mutation profiles, two patients in the ovarian cohort had negative outcomes (ERBB3 only and a patient without identified targetable mutations; Table 2), while all the patients in the cervix and endometrial groups had positive outcomes (Table 2).

Patients with gynecologic neuroendocrine tumors $(n=4)$ had a significantly lower BMI and survival than the entire cohort (Table 3). Of the genes associated with this histology per the literature, none were significantly associated with the phenotype in our cohort. Within this profile, 50\% were ovarian primaries, $25 \%$ from the cervix and $25 \%$ from the endometrium. Platinum/Etoposide, standard of care, was given to $75 \%$ of these patients; the patient with the endometrial primary was given Carboplatin/Taxol (Table 3). Two of the patients (cervix/endometrial) received radiation therapy; the patient with the ovarian tumor did not receive radiation therapy. For novel targets identified by molecular typing, the greatest number of potential targets was found in ovarian and endometrial tumors (six for each group) while three were

Table 1 Genes mutated in our cohort and found to be significant

\begin{tabular}{|c|c|c|c|c|}
\hline Gene & $n=20$ & $\begin{array}{l}p \text {-value } \\
1 \text {-tailed }\end{array}$ & $\begin{array}{l}p \text {-value } \\
\text { 2-tailed }\end{array}$ & Targeted Therapy \\
\hline ASXL1 & $3(15 \%)$ & 0.120 & 0.022 & Sorafenib (CMML with FLT3-ITD mutation and a corresponding ASXL1 mutation) ${ }^{1}$ \\
\hline ALK & $2(10 \%)$ & 0.010 & 0.022 & Crizotinib (NSCLC with ALK-EML4 fusion transformation) ${ }^{2}$; Ceritinib (NSCLC or other cancers) ${ }^{3}$ \\
\hline EGFR & $1(5 \%)$ & 0.065 & 0.130 & Erlotinib (NSCLC) ${ }^{4}$ Afatinib (NSCLC) ${ }^{5}$; Gefitinib (NSCLC) ${ }^{6}$ \\
\hline ERBB3 & $4(20 \%)$ & 0.014 & 0.028 & $\begin{array}{l}\text { MM-121 (Clinical Trial NSCLC; sensitizes to other chemo) }{ }^{7} \text {; MM-111 (Clinical Trial Breast Cancer) }{ }^{8} \text {; } \\
\text { U3-1287/AMG-888 (Clinical Trial Metastatic BCA) }\end{array}$ \\
\hline GPR124 & $4(20 \%)$ & 0.014 & 0.028 & miR-138-5p (NSCLC cell lines; sensitizes to chemo) ${ }^{10}$ \\
\hline KMT2D & $4(20 \%)$ & 0.014 & 0.130 & None currently; Aka MLL2; (Head and Neck cancer biology) ${ }^{11}$ \\
\hline NTRK1 & $2(10 \%)$ & 0.109 & 0.022 & Imatinib (Gleevec; GIST) ${ }^{12}$ \\
\hline AKAP9 & $5(25 \%)$ & 0.050 & 0.100 & None currently; (Breast, Thyroid) $)^{13,14}$ \\
\hline ASXL & $2(10 \%)$ & 0.011 & 0.241 & Sorafenib (CMML with FLT3-ITD mutation and a corresponding ASXL1 mutation) ${ }^{1}$ \\
\hline CMPK1 & $5(25 \%)$ & 0.050 & 0.100 & Deactivation of gemcitabine $^{15}$ \\
\hline MBD1 & $5(25 \%)$ & 0.050 & 0.100 & Drug resistance (Pancreatic Cancer) ${ }^{16}$ \\
\hline ROS1 & $5(25 \%)$ & 0.050 & 0.100 & Crizotinib (NSCLC) ${ }^{17}$ \\
\hline
\end{tabular}

Both 1-tailed and 2-tailed $p$-values were determined; significant 2-tailed $p$-values are considered more sensitive; bold items indicate the $p$-value for genes found to be significant between cohorts 
Table 2 Epithelial Profile

\begin{tabular}{|c|c|c|c|c|c|c|}
\hline \multirow{2}{*}{$\begin{array}{l}n=11 \\
\text { Age }\end{array}$} & & & & \multicolumn{3}{|c|}{ Genes associated with this histologic type ${ }^{c}$} \\
\hline & & & & APC & ERBB2 & NRAS \\
\hline Range & $23-40$ & & & ARID1A & FBXW7 & PIK3CA \\
\hline Mean & 33.9 & & & BRAF & FGFR2 & PPP2R1A \\
\hline Median & 36 & & & BRCA1 & KRAS & PTEN \\
\hline BMI & & & & BRCA2 & MLH1 & RNF43 \\
\hline Range & $24-61.4$ & & & CDKN2A & MSH6 & SMARCA4 \\
\hline Mean & 34 & & & CTNNB1 & MYC & TP53 \\
\hline Median & 30 & & & DNMT3A & NF1 & \\
\hline \multicolumn{7}{|l|}{ Survival } \\
\hline Range & $369-660$ & & & & & \\
\hline Mean & 542 & & & & & \\
\hline \multirow[t]{2}{*}{ Median } & 590 & & & & & \\
\hline & & Chemo & Rad & Alive & Novel Targets & Profiles \\
\hline Location & & & & & & $n=7^{\mathrm{ab}}$ \\
\hline Ovary & 7 (64\%) & Carbo/Taxol & 0 & $5(71 \%)$ & $\begin{array}{l}\text { AKAP9 (3) } \\
\text { CMPK (1) } \\
\text { MBD1 (1) } \\
\text { ASXL1 (1) } \\
\text { ERBB3 (2) } \\
\text { KMT2D (1) }\end{array}$ & $\begin{array}{l}\text { ERBB3 only }(1)^{\mathrm{a}} \\
\text { AKAP9 only (3) } \\
\text { CMPK, ASXL1 ERBB3 (1) } \\
\text { MBD1, KMT2D (1) } \\
\text { No significant genes }(0)^{\mathrm{b}}\end{array}$ \\
\hline Cervix & $2(18 \%)$ & $\begin{array}{c}\text { Carbo/Taxol (1) } \\
\text { Plat/Etop (1) }\end{array}$ & $\begin{array}{l}1 \\
1\end{array}$ & $2(100 \%)$ & 0 & $\mathrm{n} / \mathrm{a}$ \\
\hline Endometrial & $2(18 \%)$ & Carbo/Taxol & 1 & $2(100 \%)$ & $\begin{array}{l}\text { CMPK (1) } \\
\text { MBD1 (1) } \\
\text { ROS1 (1) } \\
\text { GPR124 (1) }\end{array}$ & $\begin{array}{l}\text { CMPK, MBD1 (1) } \\
\text { ROS1, GPR124 (1) }\end{array}$ \\
\hline
\end{tabular}

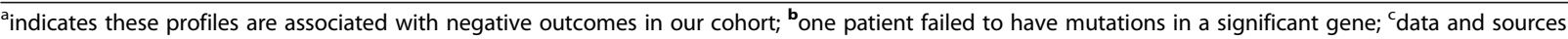
retrieved from http://cancer.sanger.ac.uk/cosmic

identified in the cervix group. In correlating outcomes with gene mutation profiles, one patient in the ovarian cohort had a negative outcome (ALK/GPR124/KMT2D; Table 2), as did one patient in the endometrial cohort (ROS1/ALK/ERBB3/GPR124/KMT2D/NTRK1). Interestingly, these two patients each displayed ALK, GPR124 and KMT2D mutations, the only overlapping mutations between these two groups. One patient in each the ovarian and the cervix cohorts had a positive outcome.

The remaining patients $(n=5)$ were categorized in the sarcoma/other group, which included three sarcomas, a germ cell tumor and a high-grade sex cord stromal tumor. Overall survival was significantly lower than the entire cohort and the other groups (259 days; Table 4). Of the genes associated with this phenotype, none were significantly associated with our cohort. Within this profile, primary tumors were in the ovary $(60 \%)$ and endometrium (40\%). Platinum/Etoposide was given to $33 \%$ of the patients with ovarian tumors; two patients $(66 \%)$ had no or unknown chemotherapy (Table 4). Of the two patients with endometrial cancers, one was given Gemzar/Taxotere, while the other patients received no therapy. None of the patients received radiation therapy. For novel targets as defined by molecular typing, the greatest number was found in ovarian tumors (six; Table 4), while three were identified in the endometrial group. In correlating outcomes with gene mutation profiles, two patients in the ovarian cohort had negative outcomes (ROS1/EGFR and ROS1/ERBB3/ KMT2D/NIRK1; Table 4), as did one patient in the endometrial cohort (GPR124 only).

In addition to mutational profiles associated with negative outcomes, mutation load, reflecting the total number of mutated genes predicted to have functional relevance (both significant and non-significant), was evaluated for each patient (Table 5). For mean mutation load, the ovarian tumors in the epithelial cohort had 22, while the neuroendocrine tumors had 27 and the sarcoma/other averages were 27 and 29, respectively. The endometrial tumors had an average mutation load of 111 in the neuroendocrine group, while the sarcoma/ other endometrial tumors had an average mutation load of 21. Interestingly, all tumors that exhibited negative outcomes were void of mutations in APC and ABL2 (Table 5). 
Table 3 Neuroendocrine Profile

\begin{tabular}{|c|c|c|c|c|c|c|}
\hline \multirow{2}{*}{$\begin{array}{l}n=4 \\
\text { Age }\end{array}$} & & & & & \multicolumn{2}{|c|}{ Genes associated with this histologic type ${ }^{b}$} \\
\hline & & & & & APC & P16 \\
\hline Range & $13-40$ & & & & FHIT & PTEN \\
\hline Mean & 29 & & & & FGFR1 & RB \\
\hline Median & 32 & & & & KRAS & sox \\
\hline BMI & & & & & MCC & TP53 \\
\hline Range & $21.5-39.5$ & & & & MEN-2 & \\
\hline Mean & 29.1 & & & & MYCL & \\
\hline Median & 27.7 & & & & & \\
\hline \multicolumn{7}{|l|}{ Survival } \\
\hline Range & $189-596$ & & & & & \\
\hline Mean & 366 & & & & & \\
\hline \multirow[t]{2}{*}{ Median } & 339.5 & & & & & \\
\hline & & Chemo & Rad & Alive & Novel Targets & Profiles \\
\hline \multicolumn{7}{|l|}{ Location } \\
\hline Ovary & $2(50 \%)$ & Plat/Etoposide & 0 & $1(50 \%)$ & $\begin{array}{l}\text { AKAP9 (1) } \\
\text { ASXL1 (1) } \\
\text { MBD1 (1) } \\
\text { ALK (1) } \\
\text { GPR124 (1) } \\
\text { KMT2D (1) }\end{array}$ & $\begin{array}{l}\text { AKAP9, ASXL1, MBD1 (1) } \\
\text { ALK, GPR124, KMT2D (1) }\end{array}$ \\
\hline Cervix & $1(25 \%)$ & Plat/Etoposide & 1 & $1(100 \%)$ & $\begin{array}{l}\text { AKAP9 (1) } \\
\text { ASXL1 (1) } \\
\text { CMPK1 (1) }\end{array}$ & AKAP9, ASXL1, CMPK1 (1) \\
\hline Endometrial & $1(25 \%)$ & Carbo/Taxol & 1 & $0(0 \%)$ & $\begin{array}{l}\text { ROS1 (1) } \\
\text { ALK (1) } \\
\text { ERBB3 (1) } \\
\text { GPR124 (1) } \\
\text { KMT2D (1) } \\
\text { NTRK1 (1) }\end{array}$ & $\begin{array}{l}\text { ROS1, ALK, ERBB3, GPR124, } \\
\text { KMT2D, NTRK1 (1) }\end{array}$ \\
\hline
\end{tabular}

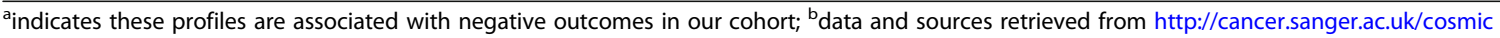

A profile predictive of outcomes in our cohort was completed using CART (Fig. 1). The mutation state of AKAP9 was the most powerful differentiation between positive and negative outcomes with AKAP9 mutations associated with positive outcomes $(n=5 ; 100 \%)$ and AKAP9 genes void of identifiable mutation (AKAP9 (-)) associated with negative outcomes. Further evaluation of negative outcomes revealed an AKAP9(-) background with synchronous MBD1, APC and/or ABL2 mutations all produced positive outcomes, while patients lacking an identified mutation in these genes had negative outcomes. The final predictive profile of negative outcomes utilizing CART was found to be AKAP9(-)/MBD1(-)/ APC(-)/ABL2(-) with a mutation load of greater than 20.5 (Fig. 1).

\section{Discussion}

Gynecologic cancers in pre-menopausal women are uncommon. We investigated the correlation between histology and tumor molecular profiles on the outcomes of 20 young women with aggressive gynecologic cancers to ascertain the possibility of targeted therapeutic options. In addition, we sought to generate an overall profile for these lesions in our cohort that more accurately reflects the complex signaling pathways associated with the cancer phenotype to investigate which mutation, or combination, is driving the biology with the hope of further expanding therapeutic options and therefore increasing response rates $[13,14]$. Typically, most targeted response scenarios are one-to-one correlations that may not suffice to maximize benefit, requiring additional information in the process of utilizing sequencing information to direct therapy. In our study, we examined the effect of multiple, interacting mutations, mutational load, and outcomes, the true clinical utility of genomic personalized medicine which hinges on the implications of these relationships [15].

\section{Evaluating outcomes}

Careful determination of outcomes for the patients in our heterogeneous cohort was completed as an integral part of our evaluation. Since all patients were members 
Table 4 Sarcoma/Other Profile

\begin{tabular}{|c|c|c|c|c|c|c|}
\hline \multicolumn{5}{|l|}{$n=5$} & \multicolumn{2}{|c|}{ Genes associated with this histologic type ${ }^{b}$} \\
\hline \multicolumn{5}{|l|}{ Age } & \multicolumn{2}{|r|}{ BRCA2 } \\
\hline Range & \multicolumn{4}{|l|}{$15-39$} & \multicolumn{2}{|r|}{ CTNNB1 } \\
\hline Mean & \multicolumn{4}{|l|}{25} & \multicolumn{2}{|r|}{ EGFR } \\
\hline Median & \multicolumn{4}{|l|}{24} & \multicolumn{2}{|r|}{ FOXL2 } \\
\hline \multicolumn{5}{|l|}{ BMl } & \multicolumn{2}{|r|}{$\mathrm{c}-\mathrm{KIT}$} \\
\hline Range & \multicolumn{4}{|l|}{$20-46.6$} & \multicolumn{2}{|r|}{ P16 } \\
\hline Mean & \multicolumn{4}{|l|}{31.6} & \multirow{2}{*}{\multicolumn{2}{|c|}{ TP53 }} \\
\hline Median & \multicolumn{4}{|l|}{23} & & \\
\hline \multicolumn{7}{|l|}{ Survival } \\
\hline Range & \multicolumn{4}{|l|}{$15-867$} & & \\
\hline Mean & \multicolumn{4}{|l|}{259.6} & & \\
\hline Median & \multicolumn{4}{|l|}{182} & & \\
\hline \multicolumn{7}{|l|}{ Cancer Type } \\
\hline Sarcoma & \multicolumn{2}{|l|}{3} & \multicolumn{2}{|c|}{ Ovary (1) Endometrial (2) } & & \\
\hline Germ Cell & \multicolumn{2}{|l|}{1} & \multicolumn{2}{|c|}{ Ovary (1) } & & \\
\hline \multirow[t]{2}{*}{ HG Sex Cord } & \multirow[t]{2}{*}{1} & & \multicolumn{2}{|c|}{ Ovary (1) } & & \\
\hline & & Chemo & Rad & Alive & Novel Targets & Profiles \\
\hline \multicolumn{7}{|l|}{ Location } \\
\hline Ovary & 3 & $\begin{array}{l}\text { Plat/Etoposide (1) } \\
\text { None (1) } \\
\text { Unknown (1) }\end{array}$ & 0 & $1(33 \%)$ & $\begin{array}{l}\text { MBD1 (1) } \\
\text { ROS1 (3) } \\
\text { EGFR (1) } \\
\text { ERBB3 (1) } \\
\text { KMT2D (1) } \\
\text { NTRK1 (1) }\end{array}$ & $\begin{array}{l}\text { MBD1, ROS1 (1) } \\
\text { ROS1, EGFR (1) } \\
\text { ROS1, ERBB3, KMT2D, } \\
\text { NTRK1 }(1)^{\mathrm{a}}\end{array}$ \\
\hline Endometrial & 2 & $\begin{array}{l}\text { Gemzar/Taxotere (1) } \\
\text { None (1) }\end{array}$ & 0 & $1(50 \%)$ & $\begin{array}{l}\text { CMPK1 (1) } \\
\text { MBD1 (1) } \\
\text { GPR124 (1) }\end{array}$ & $\begin{array}{l}\text { CMPK1, MBD1 (1) } \\
\text { GPR124 (1) }\end{array}$ \\
\hline
\end{tabular}

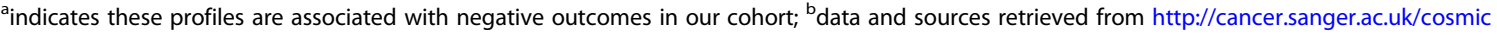

of a demographic typically void of gynecologic malignancies with histologically aggressive tumors, and understanding the small size of our cohort, patients were divided into two groups around the median survival of the entire cohort. Patients in remission during the study period were considered to have a positive outcome, as this is perhaps the best outcome a patient with any of these cancers could achieve. For patients diagnosed later within the study parameters, the progression of their disease was the deciding factor in their outcome classification despite survival less than the median: remission was denoted as positive while disease progression and death were denoted as negative. These criteria were used in an attempt to normalize the data to focus on the hypothesis that underlying genetic similarities exist within rare, aggressive tumors despite tumor origin within different cell types.

Treatment impacts outcome. As such, each cancer was treated with the standard of care for the identified histology; all molecular typing that may have suggested other effective therapeutics was done retrospectively and

Table 5 Profiles associated with a negative outcome in our cohort

\begin{tabular}{|c|c|c|c|c|c|c|}
\hline Cancer Type & Location & Chemo & Mutation Profile (significant genes) & Mutation Load ${ }^{a}$ & $A P C^{b}$ & $\mathrm{ABL} 2^{\mathrm{b}}$ \\
\hline Epithelial & Ovary & Carbo/Taxol & ERBB3 only (1) & 22 & neg & neg \\
\hline \multirow[t]{2}{*}{ NE } & Ovary & Plat/Etoposide & ALK, GPR124, KMT2D (1) & 27 & neg & neg \\
\hline & Endometrial & Carbo/Taxol & ROS1, ALK, ERBB3, GPR124, KMT2D, NTRK1 (1) & 111 & neg & neg \\
\hline \multirow[t]{2}{*}{ Sarcoma/Other } & Ovary & $\begin{array}{l}\text { Unknown } \\
\text { None }\end{array}$ & $\begin{array}{l}\text { ROS1, EGFR (1) } \\
\text { ROS1, ERBB3, KMT2D, NTRK1 (1) }\end{array}$ & $\begin{array}{l}27 \\
29\end{array}$ & neg & neg \\
\hline & Endometrial & None & GPR124 (1) & 21 & neg & neg \\
\hline
\end{tabular}

${ }^{a}$ mutation load in our cohort based on the genes in our molecular profile; ${ }^{b}$ neg indicates no mutation 


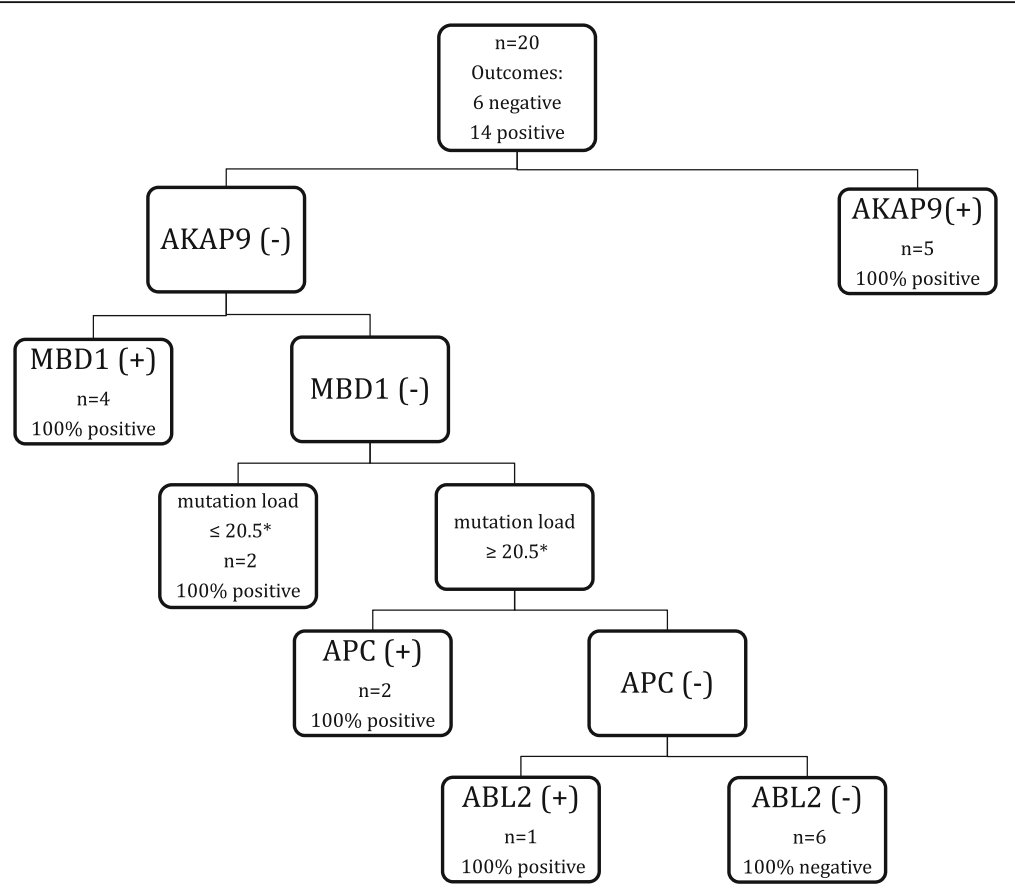

Fig. 1 CART Analysis Genetic Profile of Rare Gynecologic Cancers. Plus (+) indicates the presence of a genetic mutation; minus (-) indicates the gene has no identified mutations. All six patients with negative outcomes had the same genetic profile including no mutations in AKAP9, MBD1, APC and ABL2 but containing more than 20 mutated genes across the entire gene panel. This suggests that there are other genetic mutations responsible for the aggressive phenotype

thus, did not impact outcomes. This could explain why the clinicopathologic and treatment factors were not significantly associated with outcomes in our cohort. Due to the small study size, a larger difference would be needed to indicate statistical significance while a smaller difference in these factors in a larger population may have shown some of these variables significant. As such, we are suggesting a larger center verify our results.

\section{Genetic mutations and histology}

Functionally relevant gene mutations identified in our cohort were compared to those determined by the literature for each histologic type (Tables 2, 3 and 4). None of the gene mutations were found to correspond. All the lesions in our cohort were considered rare as they were from a young demographic typically void of gynecologic malignancies, which prompted a query into the unique attributes of these tumors collectively. Since the genesis of these lesions likely deviates from typical cancer development in terms of hormonal impetus and time to progression, alternate molecular pathway involvement is suggested. The rarity of gynecologic malignancies in this age group further suggests the involvement of similar and multiple genetic mutations impacting unique biochemical pathways in the development of these lesions despite histologic variation. In fact, the genetic analysis that identifies a common genetic profile in this diverse group suggests that, despite differing histologic origins, early and aggressive tumors may have a common molecular ontogeny. This idea correlates with the premise of individualized therapeutics that, while histologic origin is important, it is equally important to consider the expression of particular cell markers and receptors indicative of a specific molecular signature even if that particular marker or signature is typically found in a different type of cancer.

A recent study identified unique genetic signatures in early endometrial cancer of varied types that not only identifies subtypes within this histology, but also notes the genomic features that overlap with cancers of other origins, suggesting that histologic classification of tumors alone is insufficient [16]. Interestingly, many of the mutations that were found important in the genetic classification of the early endometrial subtypes overlap with ones that were found in our cohort: ARID1A, PPP2R1A and PIK3CA (which was significantly associated with outcomes in our study).

\section{Multi-gene mutational analysis}

Individually, the gene mutations with novel targets associated with the epithelial profile (Table 1) produce proteins involved in cellular growth and signaling. AKAP9, a scaffolding protein, participates in the G2/M transition, interacting with regulatory regions of various protein kinases and phosphatases [17] MBD1, a transcriptional repressor, assists in regulation of the $\mathrm{G} 2 / \mathrm{M}$ transition as well as 
regulation of PLK1 [18]. ERBB3, with known involvement in cancer development, engages MAPK, PI3K/AKT and ERK signaling pathways [19], all important in cell proliferation and differentiation, as does ROS1 [20]. ASXL1 and KMT2D (also known as MLL2), involved in transcriptional repression through histone methylation [21, 22], promotes signaling through the Wnt pathway. GPR124 promotes signaling through G-coupled receptors in Wnt and is thought to play a role in angiogenesis [23]. CMPK plays an important role in de novo pyrimidine biosynthesis [24]. In addition to the genes associated with novel targets in the epithelial group, ALK and NTRK1, paralogs involved in PI3K/AKT and MAPK signaling [25, 26] were found associated with the small sample of neuroendocrine tumors. The sarcoma/other group only had one additional targeted gene mutation, EGFR, also involved in the PI3K/ AKT signaling pathway [27].

\section{Mutation-outcome correlation}

Gene mutations resulting in alternately functioning proteins involved in immense biochemical signaling cascades may culminate in cellular phenotype and behavior alterations. As such, patterns emerged when gene mutations and patient outcomes in our cohort were correlated (Table 4). In patients with negative outcomes, mutations in four genes, either individually or in combination, were noted: ROS1, ALK, GPR124 and KMT2D (MLL2). An evaluation of how these genes impact intracellular signaling [http://string-db.org] revealed that ALK and KMT2D (MLL2) proteins appear to converge on CTNNB1, a key member of the Wnt pathway, important in cell adhesion and maintenance of an appropriate cell cycle [28] (Additional file 4: Figure S1). GPR124, ALK and KMT2D proteins converge on HSP90AA1, a key regulator in PK1 activity at the G2/M transition [24] (Additional file 5: Figure S2). Interestingly, ROS1, involved in other less well defined intracellular pathways, also interacts with HSP90AA1 and is important in the transformation of non-small cell lung cancer (NSCLC) [29].

Novel therapeutics targeting the Wnt pathway are under investigation; however, the complexity of this pathway has made single strategy therapy difficult [30], particularly due to the interconnectedness of oncogene and tumor suppressor pathways. In addition, since HSP90AA1 has been shown to stabilize several cancer proteins, it is now an attractive target for cancer therapy development [31].

\section{Mutational load}

Genomic instability (overall mutation load) acknowledges multiple mutations in complex signaling cascades effect cancer phenotypes [32] and the persistence of instability depends on DNA repair, chromosome segregation, and cell cycle checkpoints for cessation of cell cycle progression [33]. Additionally, the distribution of genetic instability differs between cancers and varies during carcinogenesis creating fluctuating instability and heterogeneity within tumors [34]. In our study, mutation load only considers functionally relevant mutations within each primary tumor, both significant and not significant in our cohort, suggesting that the presence of mutations are indicators of cellular processes that can be gauges of genetic instability, and thus, players in carcinogenesis.

While mutation load comments on relative stability of the genome, it does not infer the precise functional impact of the mutations on cellular signaling. Multiple mutations often converge to affect protein stability [35] and activity, producing truncated protein subunits without functionally relevant domains, proteins that are functional but impaired, or in some cases, less than optimal protein concentrations, diminishing their influence. These scenarios don't consider gene mutations that obliterate transcription, leaving a void in a biochemical pathway [36]. Considering mutation load in the classification of cancer has been done by other studies [16].

Taken together, the gene signature of each patient, functionally relevant mutations and mutation load, were analyzed by CART, evaluating the variables that were the best predictors of positive versus negative outcomes in our patient cohort (Fig. 1). The gene best able to stratify positive/negative outcomes was AKAP9. While typically gene mutations are thought to confer negative outcomes, all patients in our cohort with an AKAP9 mutation had a positive outcome $(n=5 ; 100 \%)$. Numerous studies illustrate that while gene mutations correlate with negative outcomes [37], mutations accompany positive prognoses, such as ERBB3 in serous ovarian cancer $[38,39]$. The theory behind this phenomenon stems from the complexity of the signaling cascade coupled with allelic burden and mutated proteins' interactions with other mutations and other pathways to attenuate the implications of individual alterations in an individual protein (Additional file 4: Figsure S1 and Additional file 5: Figsure S2) [40].

Further CART analysis indicated that, like AKAP9, mutations in MBD1, APC and ABL2 conferred positive outcomes, suggesting that these mutations may alter complimentary pathways that allow for a favorable prognosis. In addition, positive outcomes had a lower average mutation load, indicating less genomic instability than patients with negative outcomes. Overall, non-mutated AKAP9, MBD1, APC and ABL2 in conjunction with a higher mutation load were associated with negative outcomes $(n=6 ; 100 \%)$, suggesting mutations in other genes not identified in our cohort as driving the cancerous phenotype. Interestingly, 
AKAP9, MBD1 and ABL2 mutations have not been associated with gynecologic malignancies, while APC mutations has been shown to be associated with a minority of endometrial carcinomas [41].

The analysis of our cohort suggests that for rare gynecologic cancers in young women, other drivers, yet to be identified, potentially impact the development and aggressive behavior of these lesions, highlighting the complexity of cancer development. Additionally, when considering typical cancer drivers such as p53 or BRCA, is it possible that mutations in these genes 'develop' over time to create a cancerous phenotype while mutations in other genes affecting alternate biochemical pathways develop in such a manner to affect phenotype of the cancer in a manner to produce a more aggressive tumor earlier? Is it also possible that a particular mutation can cause a cascade of events to produce an aggressive phenotype in a young person and still be sporadic?

\section{Implications and future directions}

The relationships that emerge from this analysis of twenty patients and their outcomes create a new set of observations/questions outside of the one-to-one mutation:outcome paradigm. Firstly, we have documented genetic mutations that correlate with positive outcomes from standard of care chemotherapies. For these patients, would genomic sequencing and identification of mutations lead to more effective use of non-targeted therapies? Secondly, how meaningful is the finding that combinations of mutations correlate to outcomes? Can the relationship between discrete mutations that apparently interact to influence outcomes be interrogated to provide rationale to predict which mutations could plausibly influence each other and which mutation combinations do not? Lastly, this analysis merits a larger study with longer outcomes. What size of study and what additional data would be necessary to derive meaningful implications for the clinical utility of this kind of outcome correlation?

Notably, this analysis has been by design limited as to the additional information utilized to establish correlation with patient outcomes. The information comes exclusively from a fixed and somewhat reductionistic data source FFPE tissue - an archive of the genomic state of the tumor at a single time-point, the results from which are difficult to project forward into dynamic scenarios influenced by a number of poorly understood or controlled interactions. As opposed to such approaches, the recreation and/or manipulation of complex living systems themselves provides an additional source of information. The paradigm shift in in vitro techniques to three-dimensional (3D) cell culture microenvironments is demonstrating increasingly meaningful clinical correlations [42] with patient response outcomes. The use of genomic analysis to inform drug selection followed by the generation of patient-specific phenotypic, live cell drug response data then creates an entirely new source of data. When coupled with complex analysis of multiple, interacting mutations and mutational load, as has been demonstrated in the current study, it could result in particularly powerful elucidation of the complex relationship between drugs and cancer patient response.

\section{Conclusion}

We sought to generate an overall genetic profile for rare histologically aggressive gynecologic tumors in premenopausal women that more accurately reflects the complex signaling pathways associated with the cancerous phenotype in hopes of further expanding therapeutic options. Through evaluating the effect of multiple interacting mutations, mutational load and outcomes, we identified mutational patterns associated with good and bad outcomes in our cohort. Firstly, the data illustrates involvement of similar and multiple genetic mutations impacting unique biochemical pathways in the development of these lesions despite histologic variation. Within each histologic type, genes identified in our cohort did not overlap with those identified in the literature, suggesting that early and aggressive tumors may have a unique and common molecular ontogeny. Interestingly, some of the mutations that were found important in our cohort were also found important in the genetic classification of the early endometrial cancer.

The gene signature of each patient, functionally relevant mutations and mutation load were analyzed by CART, evaluating the variables that were the best predictors of positive versus negative outcomes in our patient cohort. Interestingly, mutations in AKAP9, MBD1, APC and ABL2 along with a lower average mutation load conferred positive outcomes, indicating less genomic instability than patients with negative outcomes and suggesting that these mutations may alter complimentary pathways that allow for a favorable prognosis. Non-mutated AKAP9, MBD1, APC and ABL2 in conjunction with a higher mutation load were associated with negative outcomes. Many of the gene products identified in our cohort are predicted to converge on the PI3K/AKT, MAPK and the Wnt signaling pathways, all of which are under investigation for novel therapeutics.

Overall, early and rare cancers appear to have a unique genetic signature and genomic instability, acknowledging the biochemical complexity that portends cancerous phenotypes, conflicting the one-to-one mutation:outcome paradigm. Teasing out meaningful mutations to inform drug selection followed by the generation of patient-specific phenotypic, could result in particularly powerful elucidation of the complex relationship between genetic profiles, drugs and cancer patient response. 


\section{Additional files}

Additional file 1: Table S1. Ampliseq Comprehensive Cancer Panel. (DOCX $140 \mathrm{~kb}$ )

Additional file 2: Table S2. Patient Demographics (DOCX 83 kb) Additional file 3: Table S3. Histology and Grade* (DOCX $77 \mathrm{~kb}$ ) Additional file 4: Figure S1. ALK and KMT2D (MLL2) converge on CTNNB1. An evaluation of the potential role of the gene products from mutated genes in our cohort that are associated with negative outcomes was completed to potentially identify pathways that could be targeted for novel therapy in this young group. String ${ }^{\oplus}$, a protein-protein network modeling website sponsored by the String Consortium and the Swiss Institute of Bioinformatics (SIB) [http://string-db.org], was used to postulate how the gene mutations were connected in biochemical pathways that could potentially create the carcinogenic phenotype. In our cohort, ALK and KMT2D (MLL2) gene mutations were found to be associated with both ovarian and endometrial negative outcomes in patients with neuroendocrine histology. In the String program, the ALK and KMT2D proteins, while being involved in multiple pathways, appear to converge on CTNNB1, a key member of the Wnt pathway. The Wnt pathway is important in cell adhesion and maintenance of an appropriate cell cycle and has been found to be compromised in a variety of cancers. Additionally, dysregulation of the Wnt pathway has recently been implicated in maintenance of cancer stem cells, metastasis and immune control (Zhan T et al., Oncogene 2017; 36:1461-1473). The String algorithm also revealed that HSP90AA1 is also involved in this complex pathway. HSP90AA1 has been shown to be a prognostic indicator of both liver and breast cancers. (https://www.proteinatlas.org/ENSG00000080824-HSP90AA1/pathology) (DOCX $687 \mathrm{~kb}$ )

Additional file 5: Figure S2. GPR124, ALK and KMT2D proteins converge on HSP90AA1. An evaluation of the potential role of the gene products from mutated genes in our cohort that are associated with negative outcomes was completed to potentially identify pathways that could be targeted for novel therapy in this young group. String ${ }^{\circledR}$, a protein-protein network modeling website sponsored by the String Consortium and the Swiss Institute of Bioinformatics (SIB) [http://stringdb.org], was used to postulate how the gene mutations were connected in biochemical pathways that could potentially create the carcinogenic phenotype. Gene mutations in GPR124, ALK and KMT2D (MLL2) were associated with negative outcomes in Sarcome and Neuroendocrine histologies in our cohort and converge on HSP90AA1, a chaperone protein associated with an unfavorable prognosis in both liver and breast cancers. HSP90AA1 is a key regulator in PK1 activity at the G2/M transition of the cell cycle. Inhibition of HSP90AA1 and PK1 halts progression, promoting apoptosis. [http://string-db.org]; [www.genecards.org/cgi-bin/ carddisp.pl?gene=HSP90AA1\&keywords=HSP90AA1]. Both Additional files 4 and 5: Figure S1 and S2 illustrate the complexity of the carcinogenic phenotype and illustrate the variety of pathways available if a single or even multiple pathways are blocked (DOCX $271 \mathrm{~kb}$ )

\section{Abbreviations}

ABL2: ABL2 is a cytoplasmic tyrosine kinase that plays a role in cytoskeletal rearrangements; AKAP9: The A-kinase anchor proteins (AKAPs) are a group of structurally diverse proteins which have the common function of binding to the regulatory subunit of protein kinase $\mathrm{A}$ (PKA) and confining the holoenzyme to discrete locations within the cell; ALK: The ALK gene provides instructions for making a protein called ALK receptor tyrosine kinase, which is part of a family of proteins called receptor tyrosine kinases; ANOVA: Analysis of Variance statistical test used to analyze the differences among group means; APC: The APC protein acts as a tumor suppressor; BMI: Body Mass Index; CART: Classification and Regression Tree; analysis to determine a set of if-then logical (split) conditions that permit accurate prediction or classification of cases; CMPK1: This gene encodes one of the enzymes required for cellular nucleic acid biosynthesis; EGFR: The EGFR gene provides instructions for making a receptor protein called the epidermal growth factor receptor, which spans the cell membrane so that one end of the protein remains inside the cell and the other end projects from the outer surface of the cell; ERBB3: This gene encodes a member of the epidermal growth factor receptor (EGFR) family of receptor tyrosine kinases;
ERK: Extracellular signal-regulated kinases; FFPE: Formalin-fixed, Paraffinembedded tissue; FIGO: The International Federation of Gynecology and Obstetrics (FIGO) staging systems for vulva, cervix, endometrium, and sarcomas; GPR124: Probable G-protein coupled receptor 124 gene codes for a protein that is a member of the adhesion-GPCR family of receptors; IRB: Institutional Review Board; KMT2D: The KMT2D gene, also known as MLL2, provides instructions for making an enzyme called lysine-specific methyltransferase 2D that is found in many organs and tissues of the body; MAPK: Proteins that are involved in pathways directing cellular responses to a diverse array of stimuli, such as mitogens, osmotic stress, heat shock and proinflammatory cytokines; MBD1: this gene is a member of a family of nuclear proteins that functions in transcription repression and in other protein interactions; NSCLC: Non-Small Cell Lung Cancer; NTRK1: The NTRK1 gene provides instructions for making a protein that is essential for the development and survival of neurons; this protein acts as a protein kinase involved in cell growth and survival; PI3K AKT: Pathway is an intracellular signaling pathway important in regulating the cell cycle;

Polyphen: Polymorphism Phenotyping is a tool which predicts possible impact of an amino acid substitution on the structure and function of a human protein using straightforward physical and comparative considerations. Please, use the form below to submit your query; ROS1: This proto-oncogene, highly-expressed in a variety of tumor cell lines, belongs to the sevenless subfamily of tyrosine kinase insulin receptor genes; SIFT: SIFT predicts whether an amino acid substitution affects protein function. SIFT prediction is based on the degree of conservation of amino acid residues in sequence alignments derived from closely related sequences, collected through PSI-BLAST. SIFT can be applied to naturally occurring nonsynonymous polymorphisms or laboratory-induced missense mutations. (http:// provean.jcvi.org/index.php/); TNM: The TNM Classification of Malignant Tumors is a notation system that describes the stage of a cancer which originates from a solid tumor with \alphanumeric codes. T describes the size of the original (primary) tumor and whether it has invaded nearby tissue; $\mathrm{N}$ describes nearby (regional) lymph nodes that are involved; $\mathrm{M}$ describes distant metastasis.); Wnt pathway: The Wnt signaling pathways are a group of signal transduction pathways made of proteins that pass signals into a cell through cell surface receptors

\section{Acknowledgements}

Catherine Davis and Katie Floyd assisted in data collection.

\section{Availability of data and materials}

The datasets used and/or analysed during the current study are available from the corresponding author on reasonable request.

\section{Authors' contributions}

LP: Study coordinator, author. JC: Data analysis, predictive analytics. CMGS: Genetic analysis, author, editor. MG: Treatment correlations, author, editor. DPS: Gynecologic pathologist, editor. WJE: Oncologist, editor. JE: Gynecologic surgeon, study design, editor. LEP: Principal Investigatorgei. All authors read and approved the final manuscript.

\section{Ethics approval and consent to participate}

This retrospective study received IRB approval through Health Sciences SC, Greenville Health System and given the designation Pro00034325.

\section{Consent for publication}

This manuscript does not contain any individual person's data in any form (including individual details, images or videos).

\section{Competing interests}

The authors declare that they have no competing interests.

\section{Publisher's Note}

Springer Nature remains neutral with regard to jurisdictional claims in published maps and institutional affiliations.

\section{Author details}

'Department of Obstetrics and Gynecology, Greenville Health System, Greenville, SC 29605, USA. 'Institute for Translational Oncologic Research, Greenville Health System, Greenville, SC 29605, USA. ${ }^{3}$ Pathology Consultants and Associates, 8 Memorial Medical Ct, Greenville, SC 29605, USA. ${ }^{4}$ KIYATEC, 
Inc., 900-B W Faris Rd, Greenville, SC 29605, USA. ${ }^{5}$ Greenville Health System Cancer Institute, Greenville Health System, 900 W Faris Rd, Greenville, SC 29605, USA.

\section{Received: 12 March 2018 Accepted: 26 July 2018} Published online: 04 September 2018

\section{References}

1. Siegel R, Miller KD, Jemal A. Cancer statistics, 2017. CA Cancer J Clin. 2017; 67:7-30.

2. Surveillance, Epidemiology and End Results (SEER) Cancer Statistics Fact Sheets: Ovarian Cancer, Endometrial Cancer, and Cervix Uteri Cancer. 2016. National Cancer Institute. Bethesda, MD, 2016. http://seer.cancer.gov/ statfacts/html/corp.html (accessed 16.08.15).

3. Manchana T, Ittiwut C, Kavanagh J. Targeted therapies for rare gynecological cancers. Lancet Oncol. 2010;11:685-93.

4. Jelinic P, Mueller JJ, Olvera N, Dao F, Scott SN, Shah R, Gao J, Schultz N, Gonen M, Soslow RA, Berger MF, Levine DA. Recurrent SMARCA4 mutations in small cell carcinoma of the ovary. Nat Genet. 2014;46:424-8.

5. Gerlinger M, Rowan AJ, Horswell S, Larkin J, Endesfelder D, Gronroos E, Martinez P, Matthews N, Stewart A, Tarpey P, Varela I, Phillimore B, Begum S, McDonald NQ, Butler A, Jones D, Raine K, Latimer C, Santos CR, Nohadani M, Eklund AC, Spencer-Dene B, Clark G, Pickering L, Stamp G, Gore M, Szallasi Z, Downward J, Futreal PA, Swanton C. Intratumor heterogeneity and branched evolution revealed by multiregion sequencing. N Engl J Med. 2012:366:883-92

6. Roychowdhury S, lyer MK, Robinson DR, Lonigro RJ, Wu YM, Cao X, KalyanaSundaram S, Sam L, Balbin OA, Quist MJ, Barrette T, Everett J, Siddiqui J, Kunju LP, Navone N, Araujo JC, Troncoso P, Logothetis CJ, Innis JW, Smith DC, Lao CD, Kim SY, Roberts JS, Gruber SB, Pienta KJ, Talpaz M, Chinnaiyan AM. Personalized Oncology through Integrative High-Throughput Sequencing: A Pilot Study. Sci. Transl. Med. 2011;3:111ra121.

7. Von Hoff DD, Stephenson JJ, Rosen P, Loesch DM, Borad MJ, Anthony S, Jameson G, Brown S, Cantafio N, Richards DA, Fitch TR, Wasserman E, Fernandez C, Green S, Sutherland W, Bittner M, Alarcon A, Mallery D, Penny R. Pilot study using molecular profiling of patients' tumors to find potential targets and select treatments for their refractory cancers. J Clin Oncol. 2010; 28:4877-83.

8. Kumar P, Henikoff S, Ng PC. Predicting the effects of coding nonsynonymous variants on protein function using the SIFT algorithm. Nat Protoc. 2009;4:1073-81.

9. $\mathrm{Ng} \mathrm{PC}$, Henikoff S. Accounting for human polymorphisms predicted to affect protein function. Genome Res. 2009;12:436-46.

10. Forbes SA, Beare D, Gunasekaran P, Leung K, Bindal N, Boutselakis H, Ding M, Bamford S, Cole C, Ward S, Kok CY, Jia M, De T, Teague JW, Stratton MR, McDermott U, Campbell PJ. COSMIC: exploring the World's knowledge of somatic mutations in human Cancer. Nucl Acids Res. 2015;43:D805-11.

11. Wishart DS, Knox C, Guo AC, Shrivastava S, Hassanali M, Stothard P, Chang Z, Woolsey J. DrugBank: a comprehensive resource for in silico drug discovery and exploration. Nucleic Acids Res. 2006;34:D668-72.

12. Lewis RJ. An introduction to classification and regression tree (CART) analysis. San Francisco: Annual Meeting of the Society for Academic Emergency Medicine.

13. Tsimberidou AM, Wen S, Hong DS, Wheler JJ, Falchook GS, Fu S, Piha-Paul S, Naing A, Janku F, Aldape K, Ye Y, Kurzrock R, Berry D. Personalized Medicine for Patients with Advanced Cancer in the Phase I Program at MD Anderson: Validation and Landmark Analyses. Clin. Cancer Res. 2014;20:4827-36.

14. Schwaederle M, Zhao M, Lee JJ, Eggermont AM, Schilsky RL, Mendelsohn J, Lazar V, Kurzrock R. Impact of Precision Medicine in Diverse Cancers: A Meta-analysis of Phase II Clinical Trials. J.C.O. 2015;33:3817-25.

15. Raghupathi W, Raghupathi V. Big data analytics in healthcare: promise and potential. Health Inf Science and Systems. 2014;2:3.

16. Cancer Genome Atlas Research Network, Kandoth C, Schultz N, Cherniack AD, Akbani R, Liu Y, Shen H, Robertson AG, Pashtan I, Shen R, Benz CC, Yau C, Laird PW, Ding L, Zhang W, Mills GB, Kucherlapati R, Mardis ER, Levine DA. Integrated Genomic Characterization of Endometrial Carcinoma. Nature. 2013;497:67-73.

17. Terrin A, Monterisi S, Stangherlin A, Zoccarato A, Koschinski A, Surdo NC, Mongillo M, Sawa A, Jordanides NE, Mountford JC, Zaccolo M. PKA and PDE4D3 anchoring to AKAP9 provides distinct regulation of CAMP signals at the centrosome. J Cell Biol. 2012;198:607-21.
18. Xu J, Zhu W, Xu W, Yao W, Zhang B, Xu Y, Ji S, Liu C, Long J, Ni Q, Yu X Up-regulation of MBD1 promotes pancreatic Cancer cell epithelialmesenchymal transition and invasion by epigenetic down-regulation of $\mathrm{E}$ cadherin. Curr Mol Med. 2013:13:387-400.

19. Wandinger SK, Lahortiga I, Jacobs K, Klammer M, Jordan N, Elschenbroich S, Parade M, Jacoby E, Linders JT, Brehmer D, Cools J, Daub H. Quantitative Phosphoproteomics analysis of ERBB3/ERBB4 signaling. PLoS One. 2016;11:e0146100.

20. Jun HJ, Roy J, Smith TB, Wood LB, Lane K, Woolfenden S, Punko D, Bronson RT, Haigis KM, Breton S, Charest A. ROS1 signaling regulates epithelial differentiation in the epididymis. Endocrinology. 2014;155:3661-73.

21. Gangat N, Patnaik MM, Tefferi A. Myelodysplastic syndromes: contemporary review and how we treat. Am J Hematol. 2016;91:76-89.

22. Guo C, Chen LH, Huang Y, Chang CC, Wang P, Pirozzi CJ, Qin X, Bao X, Greer PK, McLendon RE, Yan H, Keir ST, Bigner DD, He Y. KMT2D maintains neoplastic cell proliferation and global histone $\mathrm{H} 3$ lysine 4 Monomethylation. Oncotarget. 2013;4:2144-53.

23. Wang Y, Cho SG, Wu X, Siwko S, Liu M. G-protein Coupled Receptor 124 (GPR124) in Endothelial Cells Regulates Vascular Endothelial Growth Factor (VEGF)-induced Tumor Angiogenesis. Curr. Mo.I Med. 2014;14:543-54.

24. GeneCards: The Human Gene Database, www.genecards.org; accessed 16/6/1.

25. Degoutin J, Figny M, Gouzi JY. ALK activation induces Shc and FRS2 recruitment: signaling and phenotypic outcomes in PC12 cells differentiation. FEBS Lett. 2007:581:727-34.

26. Tacconelli A, Farina AR, Cappabianca L, Desantis G, Tessitore A, Vetuschi A Sferra R, Rucci N, Argenti B, Screpanti I, Gulino A, Mackay AR. Alternative splicing: a regulated tumor-promoting switch in human neuroblastoma. Cancer Cell. 2004;6:347-60.

27. Nguyen KH, Kobayashi S, Costa DB. Acquired resistance to epidermal growth factor receptor tyrosine kinase inhibitors in non-small-cell lung cancers dependent on the epidermal growth factor receptor pathway. Clin Lung Cancer. 2009;10:281-9.

28. Liu Y, Patel L, Mills GB, Lu KH, Sood AK, Ding L, Kucherlapati R, Mardis ER, Levine DA, Shmulevich I, Broaddus RR, Zhang W. Clinical Significance of CTNNB1 Mutation and Wnt Pathway Activation in Endometrioid Endometrial Carcinoma. J. Natl. Cancer Inst. 2014;106:pii: dju245.

29. Kim HR, Lim SM, Kim HJ, Hwang SK, Park JK, Shin E, Bae MK, Ou SH, Wang J, Jewell SS, Kang DR, Soo RA, Haack H, Kim JH, Shim HS, Cho BC. The frequency and impact of ROS1 rearrangement on clinical outcomes in never smokers with lung adenocarcinoma. Ann Oncol. 2013;24:2364-70.

30. Anastas JN, Moon RT. WNT signaling pathways as therapeutic targets in Cancer. Nat Rev Cancer. 2013;13:11-26.

31. Shen $H$, Zhu $H$, Song M, Tian $Y$, Huang $Y$, Zheng H, Cao R, Lin J, Bi Z, Zhong W. A Selenosemicarbazone Complex with Copper Efficiently Downregulates the 90-kDa Heat Shock Protein HSP90AA1 and its Client Proteins in Cancer Cells. BMC Cancer. 2014:14:679.

32. Carter GW, Prinz S, Neou C, Shelby JP, Marzolf B, Thorsson V, Galitski T. Prediction of phenotype and gene expression for combinations of mutations. Mol Syst Biol. 2007;3:96

33. Mannini L, Menga S, Musio A. The expanding universe of cohesion functions: a new genome stability caretaker involved in human disease and Cancer. Hum Mutat. 2010;31:623-30.

34. Campbell PJ, Yachida S, Mudie LJ, Stephens PJ, Pleasance ED, Stebbings LA, Morsberger LA, Latimer C, McLaren S, Lin ML, McBride DJ, Varela I, NikZainal SA, Leroy C, Jia M, Menzies A, Butler AP, Teague JW, Griffin CA, Burton J, Swerdlow H, Quail MA, Stratton MR, lacobuzio-Donahue C, Futreal PA. The patterns and dynamics of genomic instability in metastatic pancreatic Cancer. Nature. 2010;467:1109-13.

35. Barber TD, McManus K, Yuen KW, Reis M, Parmigiani G, Shen D, Barrett I, Nouhi Y, Spencer F, Markowitz S, Velculescu VE, Kinzler KW, Vogelstein B, Lengauer C, Hieter P. Chromatid Cohesion Defects May Underlie Chromosome Instability in Human Colorectal Cancers. Proc. Nat.l Acad. Sci. 2008;105:3443-8.

36. Compagno M, Lim WK, Grunn A, Nandula SV, Brahmachary M, Shen Q Bertoni F, Ponzoni M, Scandurra M, Califano A, Bhagat G, Chadburn A, DallaFavera $\mathrm{R}$, Pasqualucci $\mathrm{L}$. Mutations of multiple genes cause deregulation of NF-kB in diffuse large B-cell lymphoma. Nature. 2009;459:717-21.

37. Guièze $R$, Robbe $P$, Clifford $R$, de Guibert S, Pereira B, Timbs A, Dilhuydy MS, Cabes $M$, Ysebaert L, Burns A, Nguyen-Khac F, Davi F, Véronèse $L$, Combes $P$, Le Garff-Tavernier M, Leblond V, Merle-Béral H, Alsolami R, Hamblin A Mason J, Pettitt A, Hillmen P, Taylor J, Knight SJ, Tournilhac O, Schuh A. Presence of multiple recurrent mutations confers poor trial outcome of relapsed/refractory CLL. Blood. 2015;126:2110-7. 
38. Walker BA, Boyle EM, Wardell CP, Murison A, Begum DB, Dahir NM, Proszek PZ, Johnson DC, Kaiser MF, Melchor L, Aronson LI, Scales M, Pawlyn C, Mirabella F, Jones JR, Brioli A, Mikulasova A, Cairns DA, Gregory WM, Quartilho A, Drayson MT, Russell N, Cook G, Jackson GH, Leleu X, Davies FE, Morgan GJ. Mutational Spectrum, Copy Number Changes and Outcome: Results of a Sequencing Study of Patients with Newly Diagnosed Myeloma. J.C.O. 2015;33:3911-20,

39. Unger U, Denkert C, Braicu I, Sehouli J, Dietel M, Loibl S, Darb-Esfahani S. Prognostic impact of HER3 based on protein and mRNA expression in highgrade serous ovarian carcinoma. Virchows Arch. 2017;470:143-51.

40. Gale RE, Green C, Allen C, Mead AJ, Burnett AK, Hills RK, Linch DC. The Impact of FLT3 Internal Tandem Duplication Mutant Level, Number, Size and Interaction with NPM1 Mutations in a Large Cohort of Young Adult Patients with Acute Myeloid Leukemia. Blood. 2008;111:2776-84.

41. Ring KL, Bruegl AS, Allen BA, Elkin EP, Singh N, Hartman AR, Daniels MS, Broaddus RR. Germline multi-gene hereditary cancer panel testing in an unselected endometrial cancer cohort. Mod Pathol. 2016;29:1381-9.

42. Desrochers T, Shuford S, Mattingly C, Holmes L, Gevaert M, Elder J, Orr D, Corless C, Puls L, Croswell HE. Ex Vivo 3d Drug Response Profiling of Primary Human Ovarian Cancer Differentiates Treatment-naive and Relapsed Patients and Molecular Subtypes. AACR 106 ${ }^{\text {th }}$ Annual Meeting 2015. 2015 Apr:18-22. Philadelphia (PA); 2015;75:LB-282.

Ready to submit your research? Choose BMC and benefit from:

- fast, convenient online submission

- thorough peer review by experienced researchers in your field

- rapid publication on acceptance

- support for research data, including large and complex data types

- gold Open Access which fosters wider collaboration and increased citations

- maximum visibility for your research: over $100 \mathrm{M}$ website views per year

At $\mathrm{BMC}$, research is always in progress.

Learn more biomedcentral.com/submissions 